\title{
A PRINCIPIOLOGIA DA MULTIPARENTALIDADE E OS DiREITOS FUNDAMENTAIS ${ }^{1}$
}

\author{
Edilton Meireles de Oliveira Santos ${ }^{2}$ \\ Liliane Nunes Mendes Lopes ${ }^{3}$
}

\begin{abstract}
Resumo
A família experimenta novas formações, tendo como esteio o vínculo criado através do afeto entre os indivíduos nas relações. A parentalidade não pode ser entendida apenas pelos laços sanguíneos, pois perpassa por questões mais subjetivas. No conflito entre a parentalidade biológica e a socioafetiva, tem-se buscado uma solução mais digna à pessoa humana, qual seja, a coexistência de ambas, gerando a multiparentalidade. $\mathrm{O}$ artigo tem como objetivo identificar o tratamento jurídico conferido pelo Direito Brasileiro ao tema, com base nos princípios constitucionais e gerais, buscando compreender a relação entre a multiparentalidade e os direitos fundamentais. Metodologicamente utiliza-se uma abordagem qualitativa, a partir de revisão bibliográfica do campo e de análise normativa e principiológica da legislação federal e constitucional sobre o tema. Na pesquisa se demonstrou a fundamentação principiológica para o reconhecimento da multiparentalidade, pautada nos direitos fundamentais na Constituição de 1988, com foco especial na filiação. A multiparentalidade não encontra ainda respaldo expresso no ordenamento jurídico brasileiro, e a repercussão dos seus diversos efeitos merece aprofundados estudos capazes de avaliar os benefícios e prejuízos porventura gerados com o seu reconhecimento.
\end{abstract}

Palavras-Chave: Multiparentalidade. Afetividade. Direitos fundamentais. Princípios constitucionais. Parentalidade socioafetiva.

\section{INTRODUÇÃO}

Os institutos de direito privado devem ser vistos sob o olhar do direito civil constitucional e, em especial, do direito de família contemporâneo, que, por sua vez, necessita ser analisado sob este prisma. Diante desse contexto, aborda-se, neste artigo, a principiologia da multiparentalidade e os direitos fundamentais, com enfoque temporal da Constituição Federal de 1988 (CFRB/88) (BRASIL, 1988) até os dias atuais. O trabalho possui o

\footnotetext{
${ }^{1}$ Este artigo comporta resultados parciais da pesquisa financiada pela UEFS - Universidade Estadual de Feira de Santana-Bahia.

2 Pós-doutor em Direito pela Faculdade de Direito da Universidade de Lisboa. Professor de Direito Processual Civil na Universidade Federal da Bahia (UFBa). Professor de Direito na Universidade Católica do Salvador (UCSal). E-mail: edilton_meireles@uol.com.br

${ }^{3}$ Mestranda pelo Programa de Pós Graduação Stricto Sensuem Família na Sociedade Contemporânea, da Universidade Católica do Salvador (UCSal). Professora da Universidade Estadual de Feira de Santana-Ba (UEFS).E-mail: lilianenmlopes@gmail.com
} 
intuito de identificar o tratamento jurídico conferido pelo Direito Brasileiro ao tema, com base nos princípios constitucionais e gerais.

O estudo possui relevância jurídica e social uma vez que a inserção de novos arranjos familiares na sociedade brasileira e de princípios constitucionais que, a exemplo do princípio dignidade da pessoa humana, do pluralismo das entidades familiares, da igualdade dos filhos, da afetividade e da solidariedade, exigiram uma nova produção interpretativa dentro do direito civil e, em especial, do direito de família.

Inobstante a clara existência do fenômeno na sociedade, a multiparentalidade ainda traz inúmeros debates em decorrência da sua normatização e dos seus efeitos, ademais quando se constata que alguns dos novos tipos familiares não foram ainda expressamente contemplados na CFRB/88(BRASIL, 1988). Por esta razão os debates doutrinários e jurisprudenciais são de grande relevância, pois facilitam o reconhecimento social e jurídico de normas chamadas de inclusão pelo Supremo Tribunal Federal (STF) (SANTOS, 2014).

Observa-se que o Direito Brasileiro não dispõe de regulamentação legislativa específica para o fenômeno fático e não há uma pacificação doutrinária, nem jurisprudencial acerca da aplicabilidade da teoria da multiparentalidade, para reconhecer a coexistência da filiação socioafetiva e da filiação biológica com todos os seus efeitos jurídicos.

O método utilizado para a elaboração do artigo é o qualitativo, método esse de investigação científica que se foca no caráter subjetivo do objeto analisado, estudando as suas particularidades e experiências individuais. O processo desta pesquisa foi composto por duas etapas basilares que compõe essa espécie metodológica: (1) fase exploratória e (2) análise e tratamento do material empírico e documental (MINAYO, 2007; GIL, 2002). Então, de forma exploratória, a partir de revisão bibliográfica do campo e de análise normativa e principiológica da legislação federal e constitucional sobre o tema objetiva-se compreender a relação entre a multiparentalidade e os direitos fundamentais.

\section{NOÇÕES CONCEITUAIS}

\section{Transformações nas Famílias Contemporâneas}

A família é um tema explorado por diversas ciências ao longo da história humana, todavia a temática se torna atrativa e atual, porque esta se reestrutura, quebra paradigmas, mas permanece viva no seio da sociedade, tendo um importante papel. Barbosa (1998, p. 24), pontua que não importando a configuração que venha assumir, ela garante aos "novos sujeitos que se apresentam ao mundo, o direito ao amor, ao acolhimento no mundo humano e à palavra”. 
Sua conceituação é complexa nas diversas áreas do conhecimento humano. Para que se possa extrair uma percepção sociológica da família, segundo Donati (2008, p. 50-51):

É necessário o reconhecimento da existência da reciprocidade nas relações entre os sexos, com as suas consequências sobre as gerações (...) que transforma o mero grupo (família como "relação intersubjetiva") numa instituição social (família como "relação sistêmica"). Onde esse reconhecimento não existir, as relações permanecem no estágio da simples convivência (sem vínculos de reciprocidade).

Onde não houver essa relação sistêmica, haverá simples convivência, sem vínculos de reciprocidade relacional. Para o citado autor a família "é um grupo social humano primário, mas não um grupo qualquer" (DONATI, 2008, p. 50).

No campo jurídico, o conceito de família no Brasil vem sofrendo significativas alterações a partir da Constituição Federal de 1988 (BRASIL, 1988), mitigando princípios e valores, para trazer ao direito brasileiro contemporâneo um novo paradigma, lastreado nos princípios da igualdade, do afeto, da solidariedade, da dignidade da pessoa humana, dentre outros.

O antigo conceito de família hierarquizada, firmada no casamento, voltada à procriação, à afinidade e com uma rígida divisão de papéis, pautados em fundamentos utilitaristas e econômicos vem perdendo sua aplicabilidade. Este conceito de família não é, e nunca será estático, pois é reflexo do contexto histórico e social de cada época, sendo diretamente influenciado pela cultura local, modificando-se à medida que se alteram as relações sociais, culturais, geração para geração (GROENINGA, 2003). A família evoluiu do modelo hierarquizado "à linearidade dos sentimentos, à divisão de papéis, ao companheirismo e a finalidade do casamento ou da união livre passa a ser a sociedade conjugal" (BARBOSA, 1998, p. 24).

Ferreira e Espolador (2010, p. 104) afirmam que:

A família clássica, representada pelo Código Civil de 1916, extremamente hierarquizada e patriarcal, e fundada na transpessoalidade, cede espaço para a família contemporânea, que, ao contrário da codificada, tem por pressuposto, o aspecto eudemonista, ou seja, a realização pessoal de seus membros, estes ligados por laços afetivos, de comunhão de vida e de afeto.

A família contemporânea deixou de observar tanto o coletivo passando a ter um cunho mais eudemonista, voltar-se às necessidades e direitos do indivíduo, à busca do bem-estar e da dignidade pessoal, mas sem perder a essência de unidade familiar, de pertencimento ao coletivo, perseguindo um equilíbrio entre o bemestar pessoal e o social. A família deve representar o acolhimento, a realização do amor, dos sentimentos de cada indivíduo; onde o lar deve ser um lugar de construção de sonhos, afetos, afetividades e de valores como respeito e reciprocidade. (DIAS; PEREIRA, 2003).

A Carta Magna de 1988 (BRASIL, 1988) implantou um novo sistema jurídico em relação à família quando estabeleceu, no art. 226 e seus parágrafos, novos paradigmas e diretrizes, tais como: dignidade da pessoa humana; a igualdade entre os cônjuges; a igualdade entre os filhos havidos dentro ou fora do casamento, 
proibindo a discriminação entre eles; a busca da verdade parental; o reconhecimento de outras modalidades de entidades familiares, como a união estável e família monoparental. ${ }^{4}$

A Constituição Brasileira de 1988 (BRASIL, 1988) impulsionou, por conseguinte, uma nova produção interpretativa dentro do direito de civil e em especial o direito de família, representando sua evolução; houve uma maior aceitabilidade pela sociedade do pluralismo das entidades familiares.

Trouxe à baila, portanto, o surgimento da "família moderna", respaldada no suporte emocional do indivíduo. Princípios como a afetividade e a solidariedade começaram a pautar juridicamente as relações familiares, sendo tratados por alguns autores como sendo direitos fundamentais (LISBOA 2013; LÔBO, 2017; TARTUCE, 2006).

Diversos fatores contribuíram para estas modificações. A igualdade de gêneros, por exemplo, trouxe a participação das mulheres no mercado de trabalho, gerando o questionamento acerca das responsabilidades de mulheres e homens no seio familiar e a divisão de tarefas fundadas no companheirismo (GOLDANI, 2002).

Portanto, novas e variadas entidades familiares, pautadas nas mudanças de paradigmas, surgiram no Brasil. Concebe-se, atualmente, a família como nuclear, aquela constituída apenas pelas "pessoas que habitam o mesmo teto, em regra, o casal e os filhos, economicamente dependentes dos pais" (BRAUNER, 2001, p. 10).

Dentre as variadas formas, cerca de 196 (PETZOAL, 1996), temos as famílias reconstruídas, neoconfiguradas e as pluriparentais formadas pelo casamento ou união estável, com filhos de um ou de ambos os membros do casal, provenientes de vínculo (s) anterior (es) nos diversos arranjos: pais solteiros, divorciados ou viúvos. (GRISARDI FILHO, 2003).

Petzold (1996, p. 39), sob o ponto de vista relacional, dentro de uma "concepção ecológica", conceitua família como sendo "um grupo social especial, caracterizado por intimidade e por relações intergeracionais". Ademais, as autoras Dessen e Polonia também pontuam que:

Os laços de consanguinidade, as formas legais de união, o grau de intimidade nas relações, as formas de moradia, o compartilhamento de renda são algumas variáveis que, combinadas, permitem a identificação de 196 tipos de famílias, produto de cinco subsistemas resultantes da concepção ecológica de micro, meso, exo, macro e cronossistema) (PETZOAL, 1996 apud DESSEN e POLONIA, 2007, p. 23).

Sendo foco deste trabalho a parentalidade, em especial a filiação, interessante salientar que estas relações de paternidade e maternidade, segundo Petzoal (1996 apud Dessen e Polonia, 2007, p. 23) se baseiam nas relações e interações dos genitores e sofrem "influências provenientes do mesossistema", o qual compreende "a sua presença ou ausência, se eles são biológicos ou adotivos e se moram com os pais ou não”.

\footnotetext{
${ }^{4}$ Monoparental é a família formada por qualquer dos pais e seus descendentes (Fonte: CRFB/88, art. $226 \$ 4^{\circ}$ (BRASIL. Constituição Federal de 1988. Promulgada em 5 de outubro de 1988 . Disponível vol.11, nº. 03, Rio de Janeiro, 2018.pp. 1858-1880 


\section{Parentalidade}

Como observa-se, estas transformações na família contemporânea se deram não só no tocante à conjugalidade, mas também na parentalidade. As relações parentais tiveram novos paradigmas influenciados pela globalização e pelos novos modelos familiares.

Lôbo (2017) leciona que, no decorrer da sua história, os limites das relações parentais sofreram grandes mudanças, sendo influenciados pelos interesses e pelas funções que a família adotava em cada época. Para este autor, parentesco é:

a relação jurídica estabelecida pela lei ou por decisão judicial entre uma pessoa e as demais que integram o grupo familiar. A relação de parentesco identifica as pessoas como pertencentes a um grupo social que as enlaça num conjunto de direitos e deveres. É, em suma, qualidade ou característica de parente (LÔBO, 2017, p. 201)

O critério biológico sempre foi o critério legal adotado para definir a filiação no Brasil, consubstanciada na ideia da uma prévia relação sexual que gerasse uma gravidez. Na mesma toada, a maioria dos países ao longo da história também fundamentou a filiação legal nos seus ordenamentos jurídicos correlacionando a origem biológica através do casamento juridicamente fundado, e dele somente eram os filhos tidos por legítimos.

Com o advento da Constituição de 1998 (BRASIL, 1988), como supramencionado, deu-se início as alterações normativas no Brasil, através da inserção de princípios basilares da família como o da igualdade entre os cônjuges e de direitos entre os filhos. Com isto, definitivamente o matrimônio deixou de ser o único critério para definição legítima da paternidade no Brasil, tendo a Carta Magna determinado a igualdade entre os filhos de qualquer origem.

Avanços científicos e tecnológicos colaboraram e tornaram possível determinar com precisão a origem genético-biológica, através do exame de DNA. Outros avanços genéticos como a reprodução assistida homóloga, ou heteróloga ${ }^{5}$, trouxeram à baila debates sobre a primazia do vínculo biológico, surgindo, portanto, novos rumos para as famílias no século XXI e suas relações familiares, reforçando a ideia da existência da filiação socioafetiva, construção jurídica que veio por abarcar as realidades fáticas pré-existentes e por ampliar a concepção de parentesco para parentalidade. ${ }^{6}$

em:<http://www.planalto.gov.br/ccivil_03/constituicao/constituição.htm.> Acesso em: 16 de jul. 2017); DIAS, 2015; DINIZ, 2017).

${ }^{5}$ A Reprodução Assistida é um conjunto de técnicas especializadas que tem como principal objetivo viabilizar a reprodução de casais com problemas de infertilidade. Homóloga é a reprodução que utiliza o material biológico (óvulos e espermatozoides) do casal, e heteróloga quando utiliza material biológico de um doador. (Fonte: Disponível em:<http:// www.ghente.org/temas/reproducao >. Acesso em 14 de jul. 2017.)

${ }^{6}$ Parentalidade compreende todos os parentes sanguíneos e afins (parentes do cônjuge), assim como os socioafetivos, relação de parentalidade firmada pelos laços de afetos entre os membros familiares. Diferentemente de outros campos científicos, pouco se faz esta distinção no campo do direito, usa-se as terminologias parentesco e parentalidade como sinônimos. 
A classificação das espécies de filiação diverge entre os doutrinadores, todavia hodiernamente, a maioria deles reconhece a existência da filiação definida por duas vertentes, reconhecidas no Código Civil/2002 (CC/02) (BRASIL, 2002): a biológica e a civil, sendo que outros admitem uma terceira vertente a socioafetiva. A biológica oriunda dos laços de parentalidade consanguíneos. A civil ou jurídica é toda filiação oriunda do casamento (filiação presumida artigo 1597 e 1598 do CC/02) (BRASIL, 2002) ou não (filhos de viúvas, divorciadas, solteiras, companheiras) ou entre aquelas pessoas impedidas de casar e a vinculada pela adoção, nos termos da Lei Civil (CC/02, artigo 1596) (BRASIL, 2002).

A denominada filiação socioafetiva é a baseada no afeto, na posse do estado de filho (DIAS, 2015); ou posse do estado de filho afetivo (WELTER, 2004). Os doutrinadores entendem por bem não incluírem esta última espécie dentre a jurídica, por perceberem tratar-se de uma categoria à parte, já que o afeto surge nas relações de modo natural e não por ficção jurídica. Esta espécie de filiação não está ainda expressamente prevista em lei, mas largamente admitida na jurisprudência e na doutrina.

Como explica Tartuce (2006, p. 6):

[...] o afeto talvez seja apontado, atualmente, como o principal fundamento das relações familiares. Mesmo afeto não constando a expressão do Texto Maior como sendo um direito fundamental, pode-se afirmar que ele decorre da valorização constante da dignidade humana e da solidariedade.

Não é apenas a posse do estado que filho que gera a socioafetividade, mas o "exercício da autoridade parental, externado sob a roupagem de condutas objetivas como criar, educar e assistir a prole, que acaba por gerar o vínculo jurídico da parentalidade" (TEIXEIRA; RODRIGUES, 2013). As autoras enfatizam que propiciar ao filho menor acesso aos seus direitos fundamentais é o objetivo do poder familiar, salientam ainda que um pai ou mãe sociafetivo cuida de prover "as necessidades biopsíquicas do filho menor" (TEIXEIRA; RODRIGUES, 2013).

Madaleno (2007, p. 270) conceitua a filiação socioafetiva como "a real paternidade do afeto e da solidariedade; são gestos de amor que registraram a colidência de interesse entre o filho registral e o seu pai de afeto".

Atualmente, observa-se, avanços doutrinários e jurisprudenciais no direito de família, os quais se pacificam no sentido da busca da realidade parental. Dando prevalência muitas vezes ao vínculo parental socioafetivo em detrimento do biológico, e mais ainda abrindo horizontes para uma visão mais ampla e digna da parentalidade, contemplando-se a coexistência de ambos os vínculos em diversas hipóteses, como por exemplo, nos casos de adoção "à brasileira”; a qual se dá "mediante registro civil de criança, que não tem origem biológica nos declarantes", ocorre que a "convivência familiar duradoura transforma a "adoção à brasileira" em posse do estado de filho, que é espécie do gênero estado de filiação [...]", o qual não depende da declaração ser falsa ou não 
(LÔBO, 2017, p. 246).

\section{Multiparentalidade}

Como salientado, nos últimos anos surgiu um acentuado reconhecimento social pelos novos modelos de família, vindo à baila o debate acerca das diversas situações fáticas que os permeiam, trazendo, portanto, relevância social a questões como a multiparentalidade, que está a um passo desse reconhecimento social formal, por outro lado o reconhecimento jurídico deste instituto está acontecendo de maneira acelerada. É marcante pelo fato de representar o rompimento do vínculo simplesmente biológico, valorizando-se o emocional afeto que, em essência, constituiu-se no novo pilar da multiparentalidade. (SANTOS, 2014).

Diversos autores, alguns referenciados neste trabalho, apontam que os princípios da dignidade da pessoa humana; do livre desenvolvimento da personalidade; do pluralismo das entidades familiares; da afetividade; da solidariedade; da igualdade entre os filhos; da não-intervenção ou da liberdade familiar; da função social da família; do melhor interesse da criança, do adolescente e do jovem; e da realidade socioafetiva, como sendo os mais importantes para caracterizar a possibilidade de reconhecimento da multiparentalidade.

Santos (2014, p. 4) conclui que:

A sobrepujança da afetividade sobre todos os outros quaisquer vínculos, nasceu da própria relação social, pois entendeu-se que a afetividade está intrínseca ao sentimentalismo humano, não podendo ser afastada do sentimento familiar, podendo constituir-se nessa relação pela própria convivência e constituição da família. Isto impôs ao Estado o devido reconhecimento normativo e legitimação da multiparentalidade, cabendo ao mesmo aviar meios legais de resolver e implementar seus efeitos através dos caminhos principiológicos existentes na Carta Maior, inseridos pelo constituinte.

A multiparentalidade, também nominada de pluriparentalidade, e seus efeitos jurídicos ${ }^{7}$ podem ser mencionados como parte do direito no âmbito sócio-político-financeiro, firmando-se entre as últimas conquistas sociais que estão se consolidando no cenário jurídico nacional. Com o devido reconhecimento deste instituto, nenhum dos pais, seja ele afetivo (por exemplo: madrasta ou padrasto) ou biológico (pai e mãe consanguíneos) precisa ser necessariamente excluído da relação familiar, solução esta que vem sendo aviada em diversos casos pelo Judiciário.

Podem ambos, querendo, sendo viável e caracterizados os elos afetivos, assumir o papel de pais do mesmo filho, com possibilidade jurídica de terem esse direito legalmente reconhecido perante o Poder Judiciário, com todos os seus efeitos legais. O fundamento jurídico para este reconhecimento encontra guarida nos princípios constitucionais e gerais do Ordenamento Jurídico Brasileiro. 
Teixeira e Rodrigues (2010, p. 204) também comungam do entendimento de que podem coexistir os dois vínculos, os quais devem ser reconhecidos como modo de proteção aos menores em formação:

Em face de uma realidade social que se compõe de todos os tipos de família possíveis e de um ordenamento jurídico que autoriza a livre (des) constituição familiar, não há como negar que a existência de famílias reconstituídas representa a possibilidade de uma múltipla vinculação parental de crianças que convivem nesses novos arranjos familiares, porque assimilam a figura do pai e da mãe afim como novas figuras parentais, ao lado dos seus pais biológicos.

As citadas autoras enfatizam com maestria que a multiparentalidade merece acolhida pelo Poder Judiciário como uma alternativa:

[...] que melhor tutela a criança inserida em famílias reconstituídas, pois esta tem nos seus dois pais ou duas mães verdadeiras referências parentais que, uma vez suprimidas, podem lhe gerar danos desnecessários, tão somente em virtude do apego a concepções oitocentistas que não mais atendem à realidade atual (TEIXEIRA E RODRIGUES, 2010, p. 216).

Inegável é reconhecer que a multiparentalidade é intrínseca às relações familiares reconfiguradas, estando pautada na proteção à dignidade da pessoa humana.

\section{Direitos fundamentais}

Os direitos fundamentais que protegem a pessoa constam nos artigos $5^{\circ}$ a $17^{\circ}$ da Carta Magna (BRASIL, 1988), tais como a liberdade, igualdade, a vida, a segurança e a propriedade; um rol importante de direitos e garantias fundamentais protetivas ao indivíduo.

Tais normas de proteção à pessoa humana possuem eficácia imediata e horizontal, e "devem ser aplicadas nas relações entre particulares, dirigidas que são, também, aos entes privados" (TARTUCE, 2006, p. 1). Possuem eficácia também vertical, posto que devam ser respeitados e garantidos também pelo Estado em relação ao indivíduo.

Nipperdey (2012, p. 90) lecionava que os direitos fundamentais têm um sentido duplo:

Eles são, por um lado, cunhagens da imagem humana da lei fundamental e contêm uma declaração fundamental sobre a essência e o valor da personalidade humana e sua relação para com a comunidade; eles significam, por outro, porém, não somente a concretização de uma ordem de valores no sentido ético como fundamento e critério de medida para a atuação do particular e do estado, mas eles servem imediatamente à realização concreta dos valores da personalidade extremos, que devem dar a nossa ordem estatal a nota.

A efetivação dos direitos fundamentais da pessoa humana propicia a formação digna aos membros das famílias, garantindo uma convivência social e familiar pacífica, justa e solidária. Os princípios inseridos na Lei Maior contribuem na efetivação destes direitos fundamentais, portanto merecem uma análise especial como se

\footnotetext{
${ }^{7}$ A multiparentalidade produz efeitos jurídicos em relação a ambos os pais ou mães, inclusive, no tocante ao nome, a pedido de alimentos e até mesmo direito de herança.
} 
segue.

\section{PRINCIPIOLOGIA DA MULTIPARENTALIDADE}

A evolução histórica dos princípios constitucionais e gerais, e o avanço dos direitos fundamentais trouxe grande contribuição ao direito de família, e ainda traz, colaborando com a consolidação de novos tipos de famílias que surgiram no Brasil, dada a proteção que o legislador constituinte destinou as diversas formas de famílias existentes e as que surgissem.

A hermenêutica contemporânea no Direito está intimamente ligada a outras concepções teóricas acolhidas, tanto filosóficas, quanto políticas e sociológicas, de modo a alterar a formação do pensamento jurídico, principalmente nas questões familiares tão complexas e profundas.

É de importante relevo o reconhecimento da normatividade dos princípios, em especial a aceitação dos ditos princípios não expressos (implícitos), que poderiam representar o "espírito do sistema" (CALDERÓN, 2013).

Gama (2008, p. 63) enfatiza que os princípios:

são mando de otimização de caráter deontológico, ou seja, constituem a ideia do "dever ser", enquanto que os valores situam-se na visão axiológica, ou seja, intrinsecamente daquilo que realmente "e", fazendo apenas um juízo do bem e do mal.

Os princípios trazem direcionamentos tanto para a criação, quanto para a interpretação de todo o conjunto normativo, a fim de garantir o Estado Democrático de Direito, na busca de trazer segurança jurídica e pacificação social.

Sarlet (2015, p. 61-62) leciona que como fruto da personalização e positivação na CRFB/88 (BRASIL, 1988) de determinados valores básicos, os direitos fundamentais

integram, ao lado dos princípios estruturais e organizacionais (a assim denominada parte orgânica ou organizatória da Constituição), a substância propriamente dita, o núcleo substancial, formado pelas decisões fundamentais, da ordem normativa, revelando que mesmo num Estado constitucional democrático se tornam necessárias [...] certas vinculações de cunho material para fazer frente aos espectros da ditadura e do totalitarismo.

O caminho principiológico da legislação brasileira, principalmente da CRFB/88 (BRASIL, 1988), é o mais adequado para o Estado responder ao anseio social do reconhecimento de relações de filiação afetiva, assim como para reconhecer e fundamentar a multiparentalidade e os efeitos dela decorrentes, sejam eles sociais ou jurídicos.

Dos princípios existentes no ordenamento jurídico brasileiro para respaldar a multiparentalidade, o da dignidade da pessoa humana é sem sombra de dúvidas o mais importante deles. Outros princípios, porém, já elencados como o do livre desenvolvimento da personalidade; o do pluralismo das entidades familiares; o da 
afetividade; o da solidariedade; o da igualdade entre os filhos; o da não-intervenção ou da liberdade familiar; o da função social da família; o do melhor interesse e o da realidade socioafetiva, guardam peculiar importância dentre os apontados pela doutrina. Assim, adiante passa-se a abordar esses últimos princípios, deixando de enfatizar o da dignidade da pessoa humana, já que tanto estudado.

\section{Princípio do livre desenvolvimento da personalidade}

O princípio do livre desenvolvimento da personalidade está previsto expressamente no ordenamento jurídico alemão, todavia mesmo não estando expresso no texto constitucional brasileiro é defendido por muitos doutrinadores como pertencente ao ordenamento pátrio, posto que decorrente da dignidade da pessoa humana. A importância e a expressão maior do princípio da dignidade, como leciona Lôbo, ele é (2017, p. 53-54):

o núcleo existencial, que é essencialmente comum a todas as pessoas humanas, como membros iguais do gênero humano, impondo-se um dever geral de respeito, proteção e intocabilidade. [...], viola o princípio da dignidade da pessoa humana todo ato, conduta ou atitude que coisifique a pessoa [...].

Ressalte-se a personalização do direito privado trazendo à baila a necessidade de se garantir um patrimônio mínimo ao indivíduo dentro das relações familiares para garantir a sua dignidade. Ingo Sarlet (2015, p. 110) o conceitua como:

o reduto intangível de cada indivíduo e, neste sentido, a última fronteira contra quaisquer ingerências externas. Tal não significa, contudo, a impossibilidade de que se estabeleçam restrições aos direitos e garantias fundamentais, mas que as restrições efetivadas não ultrapassem o limite intangivel imposto pela dignidade da pessoa humana.

Por conseguinte, Nipperdey (2012) afirma que toda pessoa humana tem o direito de livremente desenvolver sua personalidade de modo e se tornar um ser independente e moralmente autorresponsável. Respaldando-se no princípio do livre desenvolvimento é possível

criar uma comunidade de pessoas livres e que iniciativa e intuição nos âmbitos da cultura, da ciência, da economia e do social afiançam também a configuração progressista de todas as condições de vida e a felicidade das pessoas sobre esta terra (NIPPERDEY, 2012, p. 72).

Traduz-se nas escolhas de vida, na liberdade para escolher seu cônjuge ou companheiro, se irá se casar ou não, com quem se relaciona afetivamente, na liberdade de crença, de consciência, de confissão, o direito à livre manifestação de opinião, a liberdade de reunião, de associação, de circulação, ao segredo postal e de telecomunicações, a inviolabilidade da habitação, de planejamento familiar e outros direitos fundamentais, todos no tráfego jurídico-privado (NIPPERDEY, 2012).

A liberdade que o particular tem de desenvolver sua personalidade deve ser garantida pelo Estado sem obstáculos, isto não significa que esta liberdade não tenha limites. Os limites são de ordem constitucional ou lei moral e resultam dos direitos dos outros a serem respeitados. 
Estes direitos fundamentais que a pessoa humana faz jus no desenvolvimento livre da sua personalidade tem valor universal, e tem eficácia imediata tanto horizontal como vertical, ou seja, tanto vale para os consortes jurídicos, como para o Estado; tanto o Estado precisa respeitar, como também os pares precisam respeitar-se mutuamente na busca do bem-estar social comum a todos.

Há de se salientar que esta liberdade só será realizada de modo pleno quando se levar em conta o princípio da igualdade. A finalidade da proteção dos direitos fundamentais deixa de existir, todavia em situação de desigualdade jurídica ou fática, imprescindível então a intervenção estatal para regular e igualar as relações (NIPPERDEY, 2012).

O particular, entretanto, tem autolimitações às disposições sobre sua liberdade jurídico-fundamental própria, não podendo livremente dispor ou pactuar se vier a violar sua dignidade. Não poderá contratar o particular sobre a limitação do direito de celebração de casamento, por exemplo, ou a limitação em uma ação de divórcio dos cônjuges divorciados contraírem novas núpcias. Terá o indivíduo que respeitar as reservas de lei de direitos fundamentais particulares.

As relações de parentalidade socioafetivas e de múltiplo parentesco encontram guarida no princípio do livre desenvolvimento da personalidade, posto que toda pessoa é livre para escolher os arranjos familiares nos quais quer se desenvolver e viver, firmando laços afetivos livremente e fazendo a escolha dos papéis sociais que deseja desempenhar nas relações familiares. O respeito e manutenção, pelo Estado, da dignidade das pessoas e à suas escolhas são essenciais. Daí porque regular e reconhecer a multiparentalidade é um dever fundamental.

\section{Princípio do pluralismo das entidades familiares}

O legislador constituinte acolheu os diversos núcleos familiares, principalmente o das denominadas famílias espúrias, compreendidas como as que não eram oriundas do casamento, gerando filhos incestuosos (fruto do incesto) ou adulterinos (fruto do adultério). O concubinato puro passou, com a CRFB/88 (BRASIL, 1988), a ser denominado de união estável (ou companheirismo), caracterizado pela união de duas pessoas de sexos diferentes com fins de constituição de família, desprovida das formalidades exigidas para o casamento, todavia sem possuírem os impedimentos para o casamento, respeitando a autonomia da vontade, a liberdade de autodeterminação de pessoas que optarem por esta união desprovida das formalidades do casamento. $\mathrm{O}$ concubinato passou então a ser caracterizado pelas relações de pessoas com impedimento para o casamento ou a união estável.

Atribui-se ao multiculturalismo, resultante da globalização, a facilitação para o surgimento de novos formatos de entidades familiares, englobando as relações homoafetivas, as uniões poliafetivas, a parentalidade 
socioafetiva e a multiparentalidade. Este fenômeno deve ser compreendido como a busca de fixação de parâmetros de avaliação das necessidades fundamentais do indivíduo.

Os princípios, e em especial o do pluralismo de entidades familiares, servem como baliza para o Estado Democrático de Direito legalizar e proteger esses fenômenos, "em favor da estabilização social e da produção de condições para a paz e o bem comum” (SANTOS, 2014, p. 3).

\section{Princípio da Afetividade}

A afetividade vem sendo reconhecida, há algum tempo, como princípio fundamental para a formação da família, gerando consequências significativas e concretas no direito privado. Todavia sua aceitação no campo jurídico era complexa, prevalecendo o fator consanguíneo e biológico, ante ao princípio da busca da verdade biológica.

A palavra afeto não consta explicitamente no texto constitucional, mas decorre da valorização da dignidade humana. A afetividade se sobressai sobre todos os demais vínculos, é intrínseca ao sentimento humano, traduzida pelos elos afetivos gerados no convívio familiar.

Pautado no real sentido deste princípio, ao Estado está sendo imposto o reconhecimento e a legitimação da multiparentalidade, implementando seus efeitos através do esteio principiológico existente na Constituição Federal de 1988 (BRASIL, 1988) e no ordenamento jurídico pátrio.

Santos (2014, p. 4) afirma que:

A razão maior do dever estatal é que a afetividade não se trata apenas de um laço que envolve os membros da família, mas sim de um importante princípio extraído das entranhas culturais da humanidade, originalmente forjado na alma humana para distinguir a relação de amor do simples dever de cuidar, que valoriza a eticidade, o companheirismo, as igualdades, os desejos e interesses afetivos como função precípua dentre os seus integrantes.

Especial importância tem sido dada à subjetividade e à afetividade no Direito de Família, de tal modo que não se pode mais afastar estas das relações familiares, posto que se tornaram inerentes aos laços familiares. "Cada vez mais se dá importância nas considerações das relações familiares; aliás, um outro princípio do Direito de Família é o da afetividade" (GROENINGA, 2008, p. 28).

A paternidade nasce de uma decisão espontânea, sendo um fato cultural, diferente da responsabilidade civil gerada pela coabitação sexual que resulte numa gravidez; esta "reside antes no serviço e no amor que na procriação" (VILLELA, 1979, p. 21). A identidade da filiação, assim como da parentalidade, nasce entre a liberdade e o desejo, na complexidade das relações afetivas, no convívio diário.

Lôbo (2000) afirma que a família recuperou a função de grupo unido por um desejo de comunhão de vida, por laços afetivos. Para o autor 
O princípio jurídico da afetividade faz despontar a igualdade entre irmãos biológicos e adotivos e o respeito a seus direitos fundamentais, além do forte sentimento de solidariedade recíproca, que não pode ser perturbada pelo prevalecimento de interesses patrimoniais. É o salto, à frente, da pessoa humana nas relações familiares (LÔBO, 2000, p. 3).

Dessen e Polonia (2007, p. 24) asseveram que os laços afetivos de filiação podem desencadear um "desenvolvimento saudável e padrões de interação positivos" que propiciem o ajustamento dos indivíduos aos diversos ambientes que o cercam. Salientam que, por exemplo, "o apoio parental em nível cognitivo, emocional e social, permite à criança desenvolver repertórios saudáveis para enfrentar as situações cotidianas (...)”; por outro lado este mesmo convívio pode também desencadear "problemas de ajustamento social”.

O princípio da afetividade vem sendo adotado de maneira efetiva também na jurisprudência nacional, inúmeras decisões o utilizam como fundamento jurídico, por isto diversos autores afirmam ser um princípio jurídico fundante da paternidade socioafetiva e da multiparentalidade, adequando a conceituação da família ao meio social e aos microssistemas que a cercam.

\section{Princípio da Solidariedade}

A solidariedade é objetivo fundamental da República Federativa do Brasil, inserida no art. 3o, inciso I, da Constituição Federal de 1988 (BRASIL, 1988), no intuito de buscar a construção de uma sociedade livre, justa e solidária.

Está diretamente inserida nas relações familiares, justificando o apoio mútuo tanto nos laços conjugais, quanto nos laços da parentalidade, gerando responsabilidades recíprocas de cunho material, como os alimentos, por exemplo, porém também de cunho afetivo e psicológico. O princípio da solidariedade familiar ressalte-se, implica também em respeito e consideração mútuos em relação aos componentes da família.

O legislador constituinte consagrou a solidariedade social e familiar ao prever que o Estado asseguraria a assistência à família na pessoa de cada um dos seus integrantes, criando mecanismos para coibir a violência no âmbito das suas relações, no art. 226, $\$ 8^{\circ}$, da CRFB/88 (BRASIL, 1988).

Vale enfatizar que ao se gerar deveres recíprocos aos membros da família, ultima ratio se está desincumbindo o Estado da obrigação de prover todos os direitos assegurados ao cidadão na Constituição Federal. Na seara da filiação em especial primeiro se atribui à família (portanto, primeiro aos pais) o dever de garantir com absoluta prioridade os direitos inerentes à pessoa em estágio de desenvolvimento, aos cidadãos em

\footnotetext{
${ }^{8}$ Art. 226 da CRFB/88: A família, base da sociedade, tem especial proteção do Estado. \$ 8º do mesmo artigo: O Estado assegurará a assistência à família na pessoa de cada um dos que a integram, criando mecanismos para coibir a violência no âmbito de suas relações.
} 
formação, depois à sociedade e por último ao Estado (art. 227 da CRFB/8899) (BRASIL, 1988) (DIAS, 2015).

Pautadas neste princípio da solidariedade familiar muitas decisões judiciais são exaradas, garantindo todos os direitos e deveres da relação pluriparental, caso seja configurada a afetividade na filiação não consanguínea.

\section{Princípio da Igualdade entre os filhos}

A igualdade é vista como um sub elemento da dignidade que fora vinculada pelos direitos humanos. $\mathrm{O}$ princípio da igualdade (art. $5^{\circ}$, caput da CRFB $/ 88^{10}$ ) (BRASIL, 1988) significa que todos são iguais perante a lei, todavia deve-se tratar igualmente os iguais e desigualmente os desiguais, em conformidade com suas desigualdades.

Este princípio vincula o legislador ao criar as normas e orienta o ideal de justiça, contém também a vedação de normas arbitrárias ou diferenciadoras, a proibição de qualquer tipo de discriminação. Orientam e vinculam a elaboração de "leis jurídico-privadas e garantem, sob esse aspecto, o atuar com os mesmos direitos de todos no tráfego jurídico-privado”. (NIPPERDEY, 2012, p. 53).

O art. 227, $\$ 6^{011}$, da CRFB/88 (BRASIL, 1988) e art. $1.596^{12}$ do Código Civil/02 (BRASIL, 2002) consagram especificamente o princípio da igualdade dos filhos, acabando por completo toda e qualquer classificação ou designação discriminatória, havida anteriormente com relação à origem da filiação.

Não se utiliza mais as expressões filho adulterino ou filho incestuoso, nem filho espúrio ou filho bastardo. Tanto os filhos havidos dentro como fora do casamento, assim como os filhos adotivos e aqueles havidos por inseminação homóloga ou heteróloga são iguais, tendo os mesmos direitos e qualificações.

Tartuce (2006 p. 4) leciona que:

Isso repercute tanto no campo patrimonial quanto no pessoal, não sendo admitida qualquer forma de distinção jurídica, sob as penas da lei. Trata- se, portanto, na ótica familiar, da primeira e mais importante especialidade da isonomia constitucional.

Essa isonomia entre os filhos serve para respaldar a necessidade de reconhecer a coexistência da

\footnotetext{
${ }^{9}$ Art. 227 da CRFB/88: É dever da família, da sociedade e do Estado assegurar à criança, ao adolescente e ao jovem, com absoluta prioridade, o direito à vida, à saúde, à alimentação, à educação, ao lazer, à profissionalização, à cultura, à dignidade, ao respeito, à liberdade e à convivência familiar e comunitária, além de colocá-los a salvo de toda forma de negligência, discriminação, exploração, violência, crueldade e opressão.

${ }^{10}$ Art. 50 da CRFB/88: Todos são iguais perante a lei, sem distinção de qualquer natureza, garantindo-se aos brasileiros e aos estrangeiros residentes no País a inviolabilidade do direito à vida, à liberdade, à igualdade, à segurança e à propriedade, nos termos seguintes:[...]

${ }^{11}$ Artigo 227 \$ $6^{\circ}$ da CRFB/88: Os filhos, havidos ou não da relação do casamento, ou por adoção, terão os mesmos direitos e qualificações, proibidas quaisquer designações discriminatórias relativas à filiação.

12 Art. 1.596 do CC/02: Os filhos, havidos ou não da relação de casamento, ou por adoção, terão os mesmos direitos e qualificações, proibidas quaisquer designações discriminatórias relativas à filiação.
} 
parentalidade biológica e afetiva, afastando qualquer discriminação entre os filhos afetivos e os biológicos, acolhendo a pluriparentalidade com todos os direitos decorrentes, sob pena de renunciar a história de vida, as vivências e a própria existência do ser humano no mundo e no seio familiar.

\section{Princípio da Não-intervenção ou da liberdade familiar}

O Princípio da liberdade ou da não-intervenção na ótica do direito de família guarda relação direta com o princípio da autonomia da vontade dos contratos. Está previsto no artigo 1.513 do Código Civil de $2002^{13}$ (BRASIL, 2002) no qual fica clara a proibição da intervenção na comunhão da vida instituída pela família tanto por pessoa de direito público como privado, ou seja, nem o Estado, nem um ente privado, podem intervir nas relações familiares.

Diniz (2017, p. 41) conceitua o princípio da autonomia da vontade como "o poder de estipular livremente, como melhor lhes convier, mediante acordo de vontades, a disciplina de seus interesses, suscitando efeitos tutelados pela ordem jurídica”.

A autonomia da vontade é evidente na seara familiar, pois todas as escolhas afetivas são expressas por esta autonomia. Cada membro do núcleo familiar busca autorregular seus interesses próprios.

Vale salientar, contudo que, conforme previsto no artigo 226, $\$ 7^{14}$ da CRFB/88 (BRASIL, 1988), o Estado poderá através de políticas públicas incentivar, com recursos educacionais e científicos, o planejamento familiar e o controle da natalidade de modo a permitir que a família efetive tais direitos. Todavia não poderá impor nenhum tipo de coerção sobre o controle de natalidade ou regular o planejamento familiar, que são decisões do casal, respeitando assim os princípios da dignidade da pessoa humana e da paternidade responsável.

O $\$ 8^{\circ}$ deste mesmo artigo da Carta Magna (BRASIL, 1988) prevê que "O Estado assegurará a assistência à família na pessoa de cada um dos que a integram, criando mecanismos para coibir a violência no âmbito de suas relações".

Estes dois parágrafos consagram o princípio da não intervenção, também nominado de liberdade familiar, mediante o qual as entidades familiares são livres para compor o modelo de elo afetivo que quiser.

Como todo princípio, este deve ser analisado no conjunto do ordenamento jurídico, fazendo-se a devida ponderação frente a demais princípios relativos à família, a fim de garantir a harmonização das tutelas dos direitos

\footnotetext{
${ }^{13}$ Art. 1.513 do CC/02: É defeso a qualquer pessoa, de direito público ou privado, interferir na comunhão de vida instituída pela família.

${ }^{14}$ Art. 226 da CRFB/88: A família, base da sociedade, tem especial proteção do Estado. \ 70do mesmo artigo: Fundado nos princípios da dignidade da pessoa humana e da paternidade responsável, o planejamento familiar é livre decisão do casal,
} 
fundamentais como um todo e, portanto, o direito ao reconhecimento dos múltiplos afetos familiares.

\section{Princípio da Função social da família}

O art. 226, caput da CRFB/88 (BRASIL, 1988) dispõe que a família é a base da sociedade tendo especial proteção do Estado.

A própria sociedade necessita do reconhecimento da função social da família, posto que mister se faz analisar os elos familiares dentro do contexto social e da miscelânea das diferenças regionais e culturais nas localidades em que estão inseridos. Em diversos ramos do direito privado, em especial do direito civil a função social é reconhecida e não poderia ser diferente com o direito de família e seus institutos. Os integrantes devem propiciar mecanismos para o bem-estar material, espiritual e moral dos membros, principalmente das crianças, dos adolescentes e dos jovens.

Gagliano e Pamplona (2017, p. 104) preconizam que:

De fato, a principal função da família é a sua característica de meio para a realização de nossos anseios e pretensões. Não é mais a família um fim em si mesmo, conforme já afirmarmos, mas sim o meio social para a busca da nossa felicidade na relação com o outro.

Ressalte-se que este princípio respalda principalmente o melhor interesse da criança, do adolescente e do jovem, como abaixo explanado, já que sendo pessoa em pleno desenvolvimento precisa ter o direito de livremente desenvolver sua personalidade, a fim de que se torne um ser independente, livre e autorresponsável.

Para tanto os demais membros do grupo familiar, principalmente os pais, devem cumprir suas funções, garantindo este direito na convivência familiar, e realizando "o projeto de vida e felicidade" dentro da "dimensão existencial de cada um", em especial os filhos (GAGLIANO; PAMPLONA, 2017, p. 103).

A análise da família no contexto social é de suma importância e deve fundamentar soluções e decisões judiciais, como vem ocorrendo, no sentido de adequar o direito dos membros do núcleo familiar às transformações sociais, por exemplo, fundamentando o reconhecimento da parentalidade socioafetiva ou da pluriafetiva.

\section{Princípio do Melhor interesse}

A criança após longo processo de transformação social passou de objeto de direito, relegado à propriedade, sem expressão no seio familiar, para sujeito do direito, pessoa humana, detentor de direitos de toda

competindo ao Estado propiciar recursos educacionais e científicos para o exercício desse direito, vedada qualquer forma coercitiva por parte de instituições oficiais ou privadas. 
ordem. Com o advento da Constituição Federal de 1988 (BRASIL, 1988) e do Estatuto da Criança e do Adolescente (ECA) (BRASIL, 1990) temos a criança e o adolescente elevados ao status de prioridade absoluta e prevalência, direcionando todo o ordenamento jurídico a este novo olhar.

O princípio do melhor interesse da criança, do adolescente e do jovem está previsto no art. 227, caput, da CRFB/88 (BRASIL, 1988), no artigo $6^{\circ 15}$ do ECA (BRASIL, 1990) e artigos 1.583 a $1.586^{16}$ do Código Civil (BRASIL, 2002), e serve de baliza desde a criação de normas jurídicas até decisões judiciais ou mesmo implementação de políticas públicas. Especial e ampla proteção é reservada à criança, ao adolescente e ao jovem também no seio familiar, prevalecendo sobre os demais componentes das relações familiares a que pertencem.

Vale frisar, porém, que o adolescente, entre quinze e dezoito anos, também encontra proteção na forma da Lei n. 12.852/13 (BRASIL, 2013), que cuida do Estatuto da Juventude (EJ/13). Neste caso, ao adolescente, após os 15 até os 18 anos, aplica-se o ECA (BRASIL, 1990) e, excepcionalmente, o Estatuto da Juventude (EJ/13) naquilo que "não conflitar com as normas de proteção integral do adolescente" ( $\$ 2^{\circ}$ do art. $1^{\circ}$ da Lei n. 12.852/13- EJ/13) (BRASIL, 2013). É da lógica, ainda, do sistema de proteção, estender à criança a mesma proteção dada ao jovem, conforme previsto no EJ/13 (BRASIL, 2013), desde que não conflite com regra mais favorável prevista no ECA (BRASIL, 1990). Aqui, por certo, se a regra subsidiária estabelecida no EJ/13(BRASIL, 2013), visa a aumentar a proteção do adolescente, por mais razões se tem que essa mesma proteção se estenda às crianças.

Assim, por exemplo, da mesma forma que se assegura ao jovem, assim consideradas as pessoas que tenham entre 15 e 29 anos de idade, na forma do art. 2 do EJ/13 (BRASIL, 2013), o estabelecimento de políticas públicas regidas pelos princípios "I - promoção da autonomia e emancipação dos jovens; II - valorização e promoção da participação social e política, de forma direta e por meio de suas representações; III - promoção da criatividade e da participação no desenvolvimento do País; IV - reconhecimento do jovem como sujeito de direitos universais, geracionais e singulares; V - promoção do bem-estar, da experimentação e do desenvolvimento integral do jovem; VI - respeito à identidade e à diversidade individual e coletiva da juventude; VII - promoção da vida segura, da cultura da paz, da solidariedade e da não discriminação; e VIII - valorização do diálogo e convívio do jovem com as demais gerações" (art. 2 do EJ/13) (BRASIL, 2013), essa mesma proteção, no que couber, estende-se aos menores de 15 anos.

Aqui, por razões óbvias, não seria razoável estabelecer uma proteção mais ampla ao jovem. O Estatuto da Juventude (BRASIL, 2013), assim, acaba por integrar o microssistema de proteção da criança, do adolescente e do

\footnotetext{
${ }^{15}$ Art. $6^{\circ} \mathrm{Na}$ interpretação desta Lei levar-se-ão em conta os fins sociais a que ela se dirige, as exigências do bem comum, os direitos e deveres individuais e coletivos, e a condição peculiar da criança e do adolescente como pessoas em desenvolvimento.

${ }^{16}$ Os Art. 1.583- 1586 do CC/02, são os artigos relativos a proteção dos filhos e trata de questões tais como a guarda.
} 
jovem.

Neste sentido, o poder estatal tem o dever de zelar e amparar os direitos e interesses da criança, do adolescente e do jovem, haja vista que estes pela fragilidade de pessoa em desenvolvimento não têm condições de lutar pelos mesmos e defenderem-se de abusos de qualquer espécie, imperativo é que o Estado deve buscar o melhor interesse da criança, do adolescente e do jovem acima de qualquer outro interesse.

A família aqui detém um papel importante na formação e desenvolvimento dos menores de idade e jovens, cumprindo um papel social relevante. Toda e qualquer conduta da entidade familiar, pelo pai ou mãe, ou qualquer dos seus membros, deve focar no melhor interesse da criança, do adolescente e do jovem. As consequências da dissolução de vínculos familiares são diretamente resvaladas nestes, enquanto filhos pertencentes ao núcleo familiar, podendo causa-lhes prejuízos de toda ordem.

Saliente-se a importância dos laços afetivos perpetuados no tempo, a integração e papéis desenvolvidos por cada indivíduo no seio familiar em especial o dos pais e dos filhos para o desenvolvimento da sociedade justa e solidária. A ideia de pertencimento, afeto e acolhimento familiar está intimamente ligada à estabilidade emocional do ser humano. $\mathrm{O}$ reconhecimento da multiparentalidade traz pacificação e bem-estar às famílias que vivem este formato familiar relacional, em especial as famílias neoconfiguradas.

\section{Princípio da realidade socioafetiva}

O citado princípio refere-se ao convívio da criança, do adolescente ou do jovem em relação aos demais componentes da família.

No aspecto da multiparentalidade destaca-se que o princípio se dá de maneira reiterada, não só no modelo "adoção à brasileira", e sim no âmbito da socioafetividade direta e legal. A convivência socioafetiva precisa ser fundada em laços de afeto existentes em determinada entidade familiar. (SANTOS, 2014).

O registro da criança indica sua existência no mundo jurídico e a titularidade de direitos, como sujeito ativo dentro de uma sociedade, e é pautado no vínculo biológico concedendo o "estado de filiação"; deixando à margem a afetividade entrelaçada nestas relações de paternidade, maternidade e parentalidade. Cabendo, portanto, uma avaliação fática mais humanizada, que alcance a realidade jurídica hodierna e a real proteção à criança, do adolescente ou do jovem, a legalização da multiparentalidade é, portanto, a solução mais adequada e mais digna.

Na I Jornada de Direito Civil promovida pelo CJF (Conselho da Justiça Federal) com a chancela do Superior Tribunal de Justiça (STJ), fora aprovado o Enunciado 108 que preceitua que: "No fato jurídico do nascimento, mencionado no art. 1.603, compreende- se à luz do disposto no art. 1.593, a filiação consanguínea e 
também a socioafetiva". Da mesma maneira, na III Jornada de Direito Civil a qual fora idealizada pelo mesmo STJ, em 2004, foi aprovado o Enunciado 256 que enfatiza: "a posse de estado de filho (parentalidade socioafetiva) constitui modalidade de parentesco civil". ${ }^{17}$

A afetividade impõe deveres de natureza moral e material e as consequências pelo descumprimento destes devem ser impostas juridicamente, pois não se confunde com afeto fato de cunho psicológico, a parentalidade socioafetiva uma vez reconhecida judicialmente precisa ser em sua plenitude, imputando deveres e direitos aos envolvidos na relação biológica como na relação afetiva.

O princípio da realidade socioafetiva vem fundamentando julgamentos favoráveis ao reconhecimento da paternidade socioafetiva, tornado possível o reconhecimento da multiparentalidade no Brasil, garantindo que a pessoa em formação tenha direito à parentalidade, seja ela biológica ou a afetiva, com os direitos sócio-afetivos desta decorrentes, bem como a coexistência de ambas as parentalidades.

\section{CONCLUSÃO}

A família patriarcal intervencionista pautada nos matrimônios firmados por interesses patrimoniais fora aos poucos sendo substituída pela família eudemonista, a qual intenciona o pleno desenvolvimento do bem-estar e da personalidade de seus componentes, esta surge na sociedade e é respaldada nos diversos princípios constitucionais da $\mathrm{CRFB} / 88$.

A paternidade socioafetiva era uma realidade fática sem repercussões jurídicas, todavia se tratava de um fenômeno social de tal relevância e significado que se tornou uma categoria própria, era pungente o seu reconhecimento.

Os efeitos jurídicos desta espécie de paternidade foram abalizados pelos princípios constitucionais (CRFB/88) (BRASIL, 1988), avançando a ponto de não mais haver a prevalência da paternidade biológica, passaram a prevalecer o afeto e o melhor interesse da criança, do adolescente e do jovem na doutrina e nas decisões judiciais.

A multiparentalidade nasce nesta mesma vertente protetiva dos direitos fundamentais, já que não se pode olvidar que, aviar a harmonização da paternidade biológica com a socioafetiva é garantir a autonomia da vontade, a dignidade da pessoa humana, o livre desenvolvimento da personalidade do filho, dos pais, das mães e demais parentes envolvidos nos laços de afetividade, princípio que atribuiu ao afeto os vínculos de parentesco e normativos iniciais da multiparentalidade, sendo fundamental para o deslinde de muitas questões familiares

\footnotetext{
${ }^{17}$ Fonte: TARTUCE, Flávio. Novos princípios do Direito de Família brasileiro. Revista Jus Navigandi, Teresina, ano 11, n. 1069, 5 jun. 2006. Disponível em: <https://jus.com.br/artigos/8468>. Acesso em: 27 mai. 2016.
} 
decididas pelos Tribunais Brasileiros.

O princípio da dignidade da pessoa humana é sem sombra de dúvidas o mais importante dentre os princípios existentes no ordenamento jurídico brasileiro para respaldar a multiparentalidade; todavia demonstrouse uma real correlação também com os princípios do livre desenvolvimento da personalidade; o do pluralismo das entidades familiares; o da afetividade; o da solidariedade; o da igualdade entre os filhos; o da não-intervenção ou da liberdade familiar; o da função social da família; o do melhor interesse e o da realidade socioafetiva.

Dada a atualidade do reconhecimento do instituto, a repercussão dos seus diversos efeitos, por outro lado, merece novos e aprofundados estudos capazes de avaliar os benefícios e prejuízos porventura gerados com a multiparentalidade para as famílias envolvidas.

\title{
THE PRINCIPLE OF MULTIPARENTALITY AND FUNDAMENTAL RIGHTS
}

\begin{abstract}
The family experiences new formations, having as a mainstay the bond created through the affection between individuals in relationships. Parenting can't be understood only by the blood ties, because it runs through more subjective issues. In the conflict between biological and socio-affective parenting, we have sought a more dignified solution for the human person, that is, the coexistence of both, generating multiparentality. The article aims to identify the legal treatment conferred by Brazilian Law on the subject, based on constitutional and general principles, seeking to understand the relationship between multiparentality and fundamental rights. Methodologically, a qualitative approach is used, based on a bibliographical review of the field and normative and principles analysis of federal and constitutional legislation on the subject. The research demonstrated the fundamentals for the recognition of multiparentality, based on fundamental rights in the 1988 Constitution, with a special focus on membership. Multiparentality does not yet have express support in the Brazilian legal system, and the repercussion of its various effects merits in-depth studies capable of evaluating the benefits and losses that may be generated by its recognition.
\end{abstract}

Keywords: Multiparentality; Affectivity; Fundamental rights, Constitutional principles; Socio-affective parenting.

\section{REFERÊNCIAS BIBLIOGRÁFICAS}

BARBOSA, Águida Arruda. O direito de família e a mediação familiar. In: NAZARETH, Eliana Riberti, MOTTA, Maria Antonieta Pisano (coords.). Direito de Família e Ciências Humanas. São Paulo: Editora Jurídica Brasileira. Caderno de estudos n. 11, 1998.

BRAUNER, Maria Cláudia Crespo. As novas orientações do direito de família. In: BRAUNER, Maria Cláudia Crespo (Org.). O direito de família: descobrindo novos caminhos. São Leopoldo: Autora, 2001.

BRASIL. Lei n. 12.852, de 05 de agosto de 2013. Dispõe sobre o Estatuto da Juventude e dá outras 
providências. Lex: Estatuto da Juventude. Disponível em: <http://www.planalto.gov.br/ccivil_03/_ato20112014/2013/lei/l12852.htm>. Acesso em 16 de jul. 2017.

Lei 10.406, de 10 de janeiro de 2002. Institui o Código Civil de 2002. Disponível em: <http://www.planalto.gov.br/ccivil_03/leis/2002/L10406.htm>. Acesso em 16 de jul. 2017.

Lei n. 8.069, de 13 de julho de 1990. Dispõe sobre o Estatuto da Criança e do Adolescente e dá outras providências. Lex: Estatuto da Criança e do Adolescente. Disponível em: <http://www.planalto.gov.br/ccivil_03/leis/L8069.htm>. Acesso em 16 de jul. 2017.

Constituição Federal de 1988. Promulgada em 5 de outubro de 1988. Disponível em:< http://www.planalto.gov.br/ccivil_03/constituicao/constituição.htm.> Acesso em: 16 de jul. 2017.

CALDERÓN, Ricardo Lucas. Princípio da afetividade no direito de família. Rio de Janeiro: Renovar, 2013.

DESSEN, Maria Auxiliadora; POLONIA, Ana da Costa. A família e a escola como contextos de desenvolvimento humano. Ribeirão Preto: Paidéia [online]. 2007, vol. 17, n. 36, p. 21-32. ISSN: 0103-863X. Disponível em: http://dx.doi.org/10.1590/S0103-863X2007000100003. Acesso em: 10 jan. 2017.

DIAS, Maria Berenice. Manual de direito das famílias. 10 ed. São Paulo: Revista dos Tribunais, 2015.

DINIZ, Maria Helena. Curso de Direito Civil Brasileiro: teoria das obrigações contratuais e extracontratuais. 33 ed. Vol. 3. São Paulo: Saraiva, 2017.

DONATI, Pierpaolo. Família no século XXI: abordagem relacional. Trad. João Carlos Petrini. São Paulo: Paulinas, 2008.

FERREIRA, Breezy MyazatoVizeu, ESPOLADOR, Rita de Cássia Resquetti Tarifa. O papel do afeto na formação das famílias recompostas no Brasil. In: DIAS, Maria Berenice, BASTOS, Eliene Ferreira, MORAES, Naime Márcio Martins (coords.). Afeto e estruturas familiares. Belo Horizonte: Del Rey, 2010.

GAGLIANO, Plabo Stolzer e PAMPLONA FILHO, Rodolfo. Novo Curso de Direito Civil: Direito de Família. As famílias em perspectiva constitucional. Vol. VI. 7 ed. São Paulo: Saraiva, 2017.

GAMA, Guilherme Calmon Nogueira da. Princípios Constitucionais do Direito de Família, São Paulo: Atlas, 2008.

GIL, Antônio Carlos. Como elaborar projetos de pesquisa. 4 Ed. São Paulo: Atlas, 2002.

GOLDANI, Ana Maria. Família, gênero e políticas: famílias brasileiras nos anos 90 e seus desafios como fator de proteção. Revista Brasileira de Estudos de População, v.19, n.1, jan./jun. 2002.

GRISARDI FILHO, Waldyr. Famílias reconstituídas: breve introdução ao seu estudo. In: GROENINGA, Giselle Câmara, PEREIRA, Rodrigo da Cunha. (coords.). Direito de família e psicanálise: rumo a uma nova epistemologia. Rio de janeiro: Imago, 2003, p. 255- 267.

GROENINGA, Giselle Câmara. Família: um caleidoscópio de relações. In: GROENINGA, Giselle Câmara, PEREIRA, Rodrigo da Cunha. (coords.). Direito de família e psicanálise: rumo a uma nova epistemologia. Rio de janeiro: Imago, 2003.

Direito Civil. Volume 7. Direito de Família. Orientação: Giselda M. F Novaes Hironaka. Coordenação: 
Aguida Arruda Barbosa e Cláudia Stein Vieira. São Paulo: Revista dos Tribunais, 2008.

LISBOA, Roberto Senise. Manual Elementar de Direito Civil: direito de família e das sucessões. 5 v. 8 ed. São Paulo: Revista dos Tribunais, 2013.

LÔBO, Paulo. Direito Civil: Famílias. 7 ed. São Paulo: Saraiva, 2017.

Princípio jurídico da afetividade na filiação. Revista Jus Navigandi, Teresina, ano 5, n. 41, 1 maio 2000.

Disponível em: <https://jus.com.br/artigos/527>. Acesso em: 22 jun. 2016.

MADALENO, Rolf. Repensando o direito de família. Porto Alegre: Livraria do Advogado, 2007.

MINAYO, M.C. et al. Pesquisa social: Teoria, método, criatividade. Rio de Janeiro: Vozes, 2009.

NIPPERDEY, Hans Carl. Direitos fundamentais e direito privado. Trad. Luís Afonso Heck. In: DÜRIG, Gunter et al. Direitos fundamentais e direito privado. Textos clássicos. Luís Afonso Heck (org./revisor). Porto Alegre: Sergio Fabris, 2012.

Livre desenvolvimento da personalidade. Trad. Luís Afonso Heck. In: DÜRIG, Gunter et al. Direitos fundamentais e direito privado. Textos clássicos. Luís Afonso Heck (org./revisor). Porto Alegre: Sergio Fabris, 2012.

PEREIRA, Rodrigo da Cunha; DIAS, Maria Berenice. Direito de família e o novo Código Civil. $3^{a}$ ed. Belo Horizonte: Del Rey, 2003.

PETZOLD, Matthias. The psychological definition of "the family". CUSINATO, In: M. (Org.), Research Family: Resources and needs across the world. Milão: LED-Edizioni Universitarie, 1996, p. 25-44.

SANTOS, José Neves dos. Multiparentalidade: reconhecimento e efeitos jurídicos. Revista Jus Navigandi, Teresina, ano 19, n. 4093, 15 set. 2014. Disponível em: <https://jus.com.br/artigos/29422>. Acesso em: 27 mai. 2016.

SARLET, Ingo Wolfgang. A eficácia dos direitos fundamentais. 12 ed. Porto Alegre: Livraria do Advogado, 2015.

TARTUCE, Flávio. Novos princípios do Direito de Família brasileiro. Revista Jus Navigandi, Teresina, ano 11, n. 1069, 5 jun. 2006. Disponível em: https://jus.com.br/artigos/8468. Acesso em: 27 mai. 2016.

TEIXEIRA, Ana Carolina Brochado; RODRIGUES, Renata de Lima. O direito das famílias entre a norma e a realidade. São Paulo: Atlas, 2010.

A multiparentalidade como nova estrutura de parentesco na contemporaneidade. E-Civitas - Revista Científica do Departamento de Ciências Jurídicas, Políticas e Gerenciais do UNI-BH - Belo Horizonte, volume VI, número 2, dezembro de 13 - ISSN: 1984-2716. Disponível em: www.unibh.br/revistas/ecivitas. Acesso em: 20 mai. 2016.

VILLELA, João Baptista. Desbiologização da paternidade. Revista da Faculdade de Direito da Universidade Federal de Minas Gerais. Ano XXVII, no 21. Belo Horizonte, 1979. Disponível em: https://www.direito.ufmg.br/revista/index.php/revista/article/view/1156. Acesso em: 18 jul. 2017. 
WELTER, Belmiro Pedro. Inconstitucionalidade do Processo de Adoção Judicial.2004. Disponível em: <http://www.mundojuridico.adv.br>. Acesso em: 20 de nov. 2016.

Trabalho enviado em 23 de outubro de 2017.

Aceito em 24 de julho de 2018. 